\title{
ANALISIS SISTEM INFORMASI AKADEMIK BERBASIS SMS GATEWAY PADA FAKULTAS TEKNOLOGI INFORMASI DAN KOMUNIKASI UNIVERSITAS SEMARANG
}

\author{
Henny Indriyawati \\ Program Studi Teknik Informatika \\ Jurusan Teknologi Informasi, Universitas Semarang
}

\begin{abstract}
Abtract - Sistem akademik di universitas merupakan sistem untuk menampung datadata yang yang berhubungan dengan mahasiswa, salah satunya adalah nilai. Nilai mahasiswa Fakultas Teknologi Informasi dan Komunikasi telah diolah oleh Sistem Informasi Akademik Universitas Semarang (SIA USM) yang selanjutnya bisa diakses oleh mahasiswa. Penyampaian informasi nilai saat ini mahasiswa harus mengakses web site sia untuk mendapatkan informasi nilai, hal tersebut kurang efektif dan efisien. Dengan adanya Sistem Informasi Akademik berbasis SMS Gateway dapat mempermudah mahasiswa dalam memperoleh informasi nilai. Data yang digunakan dalam penelitian ini adalah data primer yang dilakukan dengan cara wawancara dengan pihak terkait dan data sekunder yaitu data pelengkap seperti buku-buku, literatur dan sumber tertulis lainnya.
\end{abstract}

Keywords - SMS, Gammu, SIA, SMS Gateway

\section{PENDAHULUAN}

Perkembangan teknologi informasi saat ini berkembang dengan pesatnya. Hal ini dibuktikan dengan banyaknya teknologi yang ditawarkan untuk menunjang kebutuhan dan kemudahan yang ditawarkan kepada pengguna. Saat ini teknologi tidak dapat dipisahkan dalam kehidupan manusia.

Informasi dan komunikasi merupakan kebutuhan dasar atau hakiki yang sangat penting bagi kelangsungan hidup manusia sebagai makhluk sosial. Komunikasi dibutuhkan manusia untuk memberi dan menerima atau proses pertukaran informasi dari dan kepada individu - individu yang terlibat di dalamnya. Pesatnya perkembangan zaman membuat kebutuhan media komunikasi untuk mendapatkan informasi secara tepat waktu menjadi semakin meningkat, salah satu teknologi yang digunakan yaitu SMS ( Short Message Service).

SMS (Short Message Service) merupakan salah satu metode komunikasi yang sering digunakan saat ini, SMS adalah layanan yang disediakan oleh operator telepon untuk mengirim dan menerima pesan singkat. SMS dinilai sangat praktis, murah,dan efisien karena pengguna ponsel saat ini dapat dikatakan bahwa setiap SMS yang masuk kemungkinan besar atau bahkan pasti akan dibaca karena sifat ponsel yang personal. Selain untuk mengirim pesan antar pengguna ponsel,SMS juga cocok untuk diterapkan dan berinteraksi dengan suatu sistem informasi berbasis komputer.

Nilai mahasiswa Fakultas Teknologi Informasi dan Komunikasi telah diolah didalam sistem informasi akademik, dalam penyampaian informasi nilai mahasiswa harus mengakses ke web (www.sia.usm.id), hal tersebut menimbulkan kendala bagi mahasiswa yang tidak biasa mengakses internet dan membuat mahasiswa terlambat menerima informasi. Berdasarkan masalah tersebut maka perlu dibangun sarana SMS Gateway untuk memudahkan mahasiswa dalam menerima informasi nilai. 


\section{TINJAUAN PUSTAKA}

a. Sistem Informasi

Sistem informasi adalah seperangkat komponen yang saling berhubungan yang berfungsi mengumpulkan, memproses, menyimpan dan mendistribusikan informasi untuk mendukung pembuatan keputusan dan pengawasan dalam organisasi

b. SMS

Short Message Service (SMS) adalah kemampuan untuk mengirim dan menerima pesan dalam bentuk teks dari dan kepada telepon genggam. Teks tersebut bisa terdiri dari kata-kata, nomor atau kombinasi alphanumeric. SMS merupakan sebuah layanan yang banyak diaplikasikan pada sistem komunikasi tanpa kabel, memungkinkan dilakukannya pengiriman pesan dalam bentuk alphanumeric antara terminal pelanggan atau antar terminal pelanggan dengan sistem eksternal, seperti e-mail, paging, voice mail, dan lain-lain.

c. SMS Gateway

SMS Gateway adalah sebuah perangkat lunak yang menggunakan bantuan komputer dan memanfaatkan teknologi seluler yang diintegrasikan guna mendistribusikan pesan-pesan yang digenerate lewat sistem informasi melalui media SMS yang di-handle oleh jaringan seluler (Wawan, 2010). Alur SMS Gateway dapat dilihat pada gambar di bawah ini :

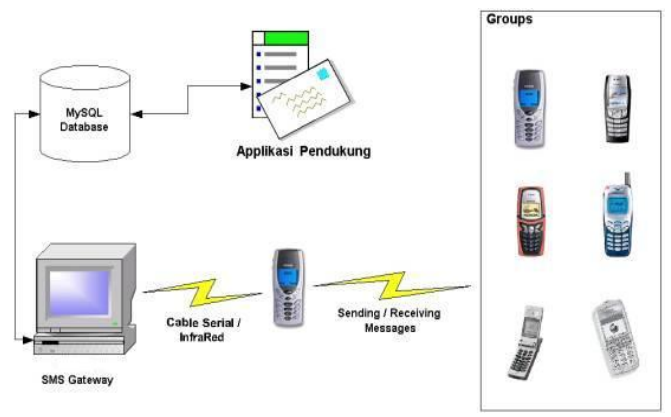

Gambar 1. Alur SMS Gateway

(David, 2010)
Gammu adalah nama sebuah project yang ditujukan untuk membangun aplikasi, script dan drivers yang dapat digunakan untuk semua fungsi yang memungkinkan pada telepon seluler atau alat sejenisnya. Sekarang gammu telah menyediakan codebase yang stabil dan mapan untuk berbagai macam model telepon yang tersedia di pasaran dibandingkan dengan project sejenis. Gammu merupakan project yang berlisensi GNU GPL 2 sehingga menjamin kebebasan menggunakan tool ini tanpa perlu takut dengan masaah legalitas dan biaya yang mahal yang harus dikeluarkan. Gammu mendukung berbagai macam model telepon seluler dengan berbagai jenis koneksi dan type (Ashri, 2010).

\section{METODE PENELITIAN}

a. Teknik Pengumpulan Data

- Wawancara

Melakukan wawancara dengan pihak-pihak terkait yaitu mahasiswa dan kepala Pusat Sistem Informasi Terpadu Universitas Semarang yaitu Saiful Hadi, M.Kom

- Pengamatan

Mengamati objek secara langsung, data yang diperoleh adalah entitas, atribut beserta relasi yang dibutuhkan dalam membangun sistem.

- Studi Pustaka

Studi pustaka dilakukan dengan cara mempelajari literatur-literatur dan bukubuku yang berhubungan dengan penelitian.

b. Jenis Data

- Data Primer

Data yang diperoleh secara langsung dari objek penelitian antara lain data mahasiswa dan nilai

- Data Sekunder

Adalah data yang diperoleh dari buktibukti dan literatur yang mendukung

d. Gammu 


\section{ANALISA dan PERANCANGAN}

1) Analisa Kebutuhan Hardware

1) Processor Core i3

2) Memori $2 \mathrm{~Gb}$

3) Harddisk yang digunakan $250 \mathrm{~Gb}$

4) Monitor VGA

5) Keyboard dan Mouse

6) Telepon genggam

7) Modem Huawei + Kartu Perdana

2) Analisa Kebutuhan Software

1) SO Windows 7

2) Gammu SMS Gateway

3) Driver installer modem Huawei

4) BrowserInternet ( Firefox, IE atau Google Chrome)

3) Deskripsi Sistem

Sistem Informasi Akademik yang sudah menyimpan data mahasiswa antara lain nilai yang sudah diolah, data diolah melalui PHP melalui API oleh admin untuk dikirimkan ke user melalui sms.

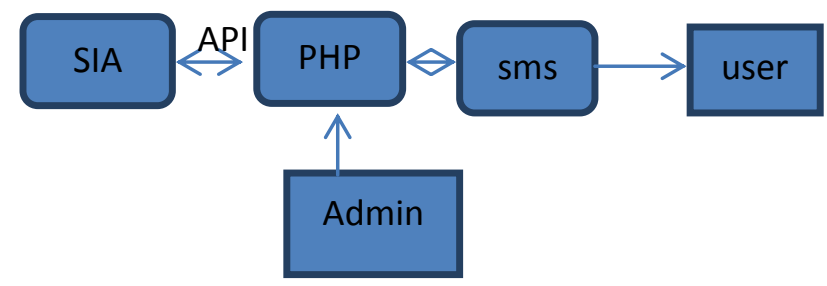

Gambar 2. Alur Sistem Sistem Informasi akademik berbasis SMS

4) Use Case Diagram

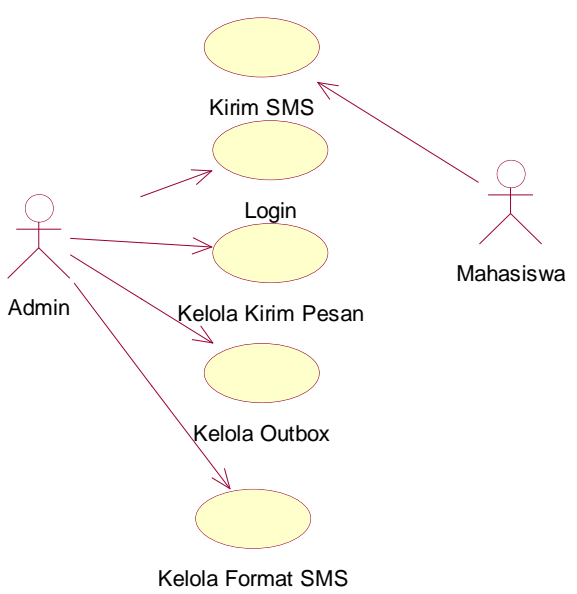

Gambar 3. Use Case SIA SMS

5) Activity Diagram

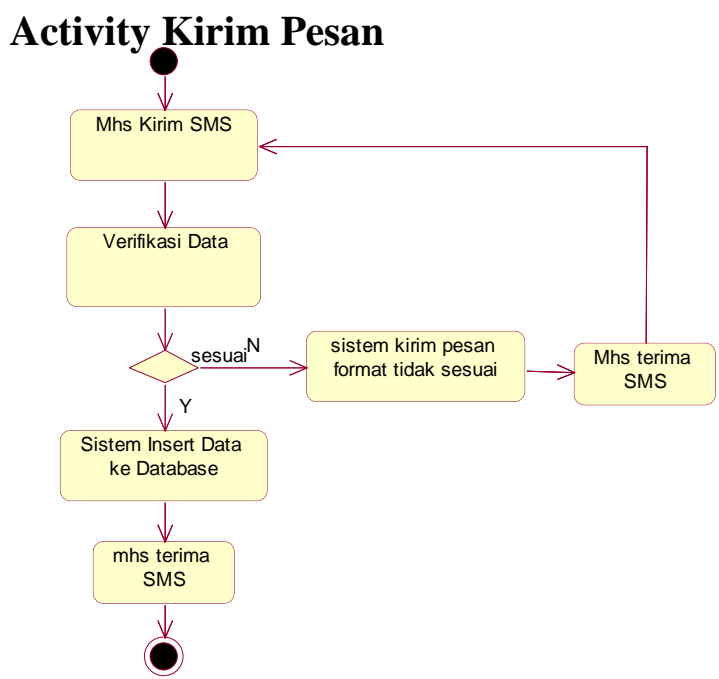

Gambar 4. Activity Kirim Pesan

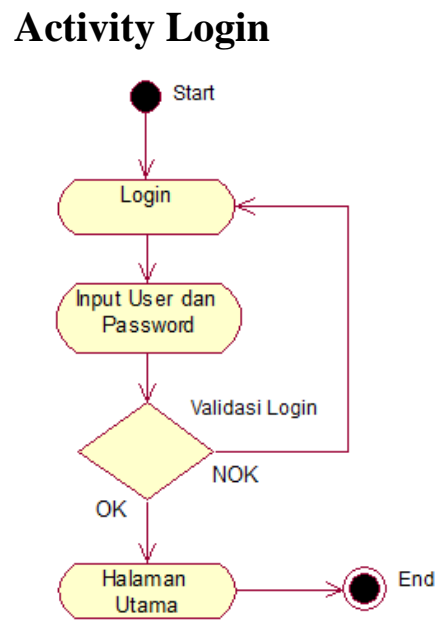

Gambar 5. Activity Login

\section{Activity Kirim Pesan}

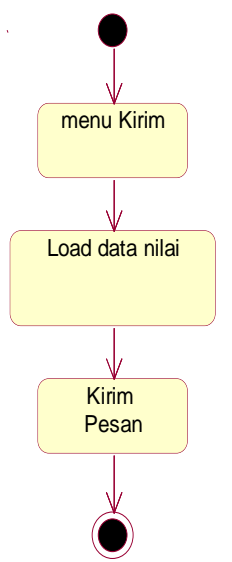

Gambar 6. Activity Kirim Pesan 


\section{Activity Outbox}

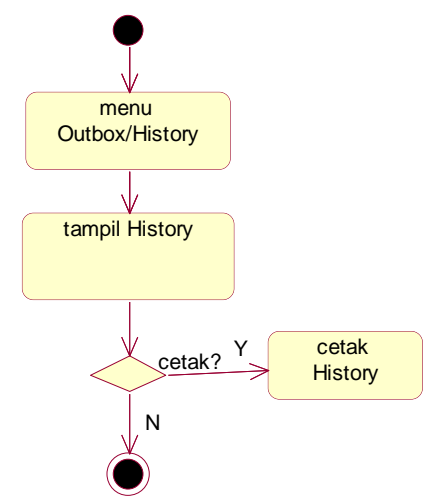

Gambar 7. Activity Outbox

\section{Activity Kelola Format SMS}

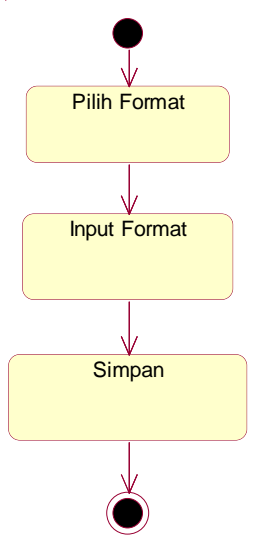

\section{Format SMS}

Model SIA SMS Gateway ini dirancang Auto Reply, format penulisan untuk request nilai adalah NILAI_NIM_MK contoh:

NILAI_G.111.14.0012_KecerdasanBuatan

\section{Kelemahan Dan Keuntungan Sistem}

- Kelemahan Sistem

1) Biaya perancangan mahal

2) Perancangan membutuhkan waktu yang relatif

3) Sebagian aplikasi masih belum dapat digunakan karena mengingat terbatasnya waktu perancangan.
- Keuntungan Sistem

1) Biaya operasional rendah

2) Penyampaian informasi cepat dan akurat.

3) Hemat waktu, tenaga dan biaya

6) Class Diagram

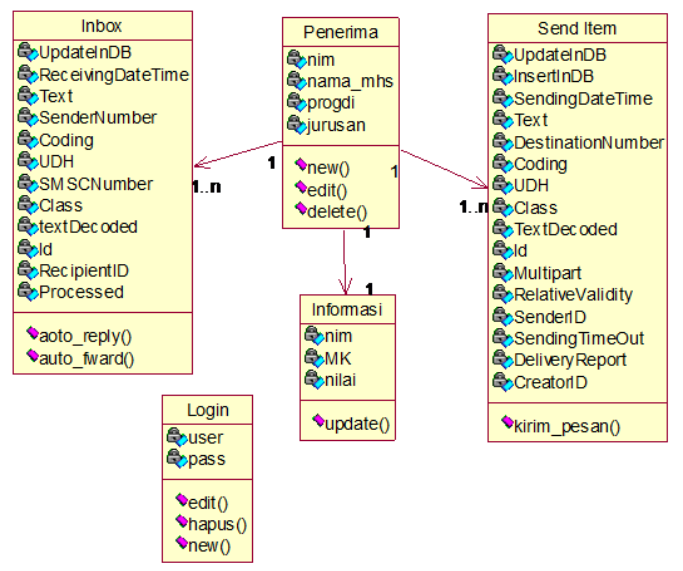

Gambar 9. Class Diagram

\section{KESIMPULAN dan SARAN}

Berdasarkan pembahasan diatas dapat disimpulkan:

a. Sistem Informasi Akademik membantu mahasisawa dalam memperoleh informasi nilai.

b. Analisis sistem akademik SMS membantu agar informasi dapat sampai ke mahasiswa dengan cepat.

Berdasarkan kesimpulan diatas, maka diharapkan:

a) Sistem ini masih banyak kekurangan, ada baiknya dibuat tampilan lebih menarik.

b) Dilakukan perbaikan dan pengembangan lebih baik agar sistem akademik berbasis SMS mempunyai nilai lebih bagi mahasiswa selain informasi nilai. 


\section{DAFTAR PUSTAKA}

[1] Agustinus, David, "Implementasi SMS Gateway Berbasis PHP Dan Gammu Pada PLTU Labuan", Bagian IT, PT PLN (Persero) Pembangkitan Lontar, 2010.

[2] Jogiyanto, HM., "Analisis dan Desain Sistem Informasi: Pendekatan Terstruktur Teori dan Praktik Aplikasi Bisnis", Andi : Yogyakarta, 2005.

[3] Ludiyanto, Wawan, "Notifikasi Layanan Pengiriman Email Masuk Berbasis SMS Gateway", Program Studi Sistem Informasi, Universitas Pembangunan Nasional, 2010.

[4] Rumbough, "The Unified Modeling Language ReferenceManual", Addison-Wesley, 1999.

[5] Rosa A.S. dan M. Shalahuddin, "Rekayasa Perangkat Lunak", Bandung: Informatika, 2013. 